\title{
Reggies/Flotillins Regulate Retinal Axon Regeneration in the Zebrafish Optic Nerve and Differentiation of Hippocampal and N2a Neurons
}

\author{
Christina Munderloh, Gonzalo P. Solis, Vsevolod Bodrikov, Friederike A. Jaeger, Marianne Wiechers, \\ Edward Málaga-Trillo, and Claudia A. 0. Stuermer \\ Department of Biology, University of Konstanz, D-78457 Konstanz, Germany
}

\begin{abstract}
The reggies/flotillins_-proteins upregulated during axon regeneration in retinal ganglion cells (RGCs) — are scaffolding proteins of microdomains and involved in neuronal differentiation. Here, we show that reggies regulate axon regeneration in zebrafish (ZF) after optic nerve section (ONS) in vivo as well as axon/neurite extension in hippocampal and N2a neurons in vitro through signal transduction molecules modulating actin dynamics. ZF reggie-1a, -2a, and -2b downregulation by reggie-specific morpholino (Mo) antisense oligonucleotides directly after ONS significantly reduced ZF RGC axon regeneration: RGC axons from reggie Mo retinas were markedly reduced. Moreover, the number of axon-regenerating RGCs, identified by insertion of A488-coupled dextran, decreased by $69 \%$ in retinas $7 \mathrm{~d}$ after Mo application. At 10 and $14 \mathrm{~d}$, RGCs decreased by 53 and 33\%, respectively, in correlation with the gradual inactivation of the Mos. siRNA-mediated knockdown of reggie- 1 and -2 inhibited the differentiation and axon/neurite extension in hippocampal and N2a neurons. N2a cells had significantly shorter filopodia, more cells had lamellipodia and fewer neurites, defects which were rescued by a reggie-1 construct without siRNA-binding sites. Furthermore, reggie knockdown strongly perturbed the balanced activation of the Rho family GTPases Rac1, RhoA, and cdc42, influenced the phosphorylation of cortactin and cofilin, the formation of the N-WASP, cortactin and Arp3 complex, and affected p38, Ras, ERK1/2 (extracellular signal-regulated kinases 1 and 2), and focal adhesion kinase activation. Thus, as suggested by their prominent re-expression after lesion, the reggies represent neuron-intrinsic factors for axon outgrowth and regeneration, being crucial for the coordinated assembly of signaling complexes regulating cytoskeletal remodeling.
\end{abstract}

\section{Introduction}

Successful axon regeneration after nerve lesion depends primarily on two factors: a permissive environment and re-expression of growth-associated proteins in the neurons (Fawcett, 1992; Stuermer et al., 1992) for the formation of new axons. Glial cell inhibitors near lesioned axons, such as Nogo and the glial scar, block axon regeneration in the mammalian CNS (Chen et al., 2000; Kim and Snider, 2008), however, not in fish (Diekmann et al., 2005) where retinal ganglion cell (RGC) axons regenerate to full recovery of function. Moreover, axotomized neurons in the fish CNS possess remarkable neuron-intrinsic properties in that they re-express growth-associated proteins to promote axon regeneration. Among such proteins are transcription factors, GAP43 , several cell adhesion molecules, cytoskeletal proteins, and the reggies/flotillins (for review, see Stuermer and Leppert, 2000; Langhorst et al., 2005).

Reggie-1 and reggie-2 were discovered in our lab as proteins upregulated in RGCs after optic nerve section (ONS) in goldfish

Received Feb. 20, 2009; revised April 15, 2009; accepted April 20, 2009

This work was supported by grants from the Deutsche Forschungsgemeinschaft and the Fonds der Chemischen Industrie. We thank Anette Y. Loos for zebrafish care and Yvonne Schrock for preparing cell cultures.

Correspondence should be addressed to Claudia A. 0. Stuermer, Department of Biology, University of Konstanz, Universitaetstrasse 10, D-78457 Konstanz, Germany. E-mail: Claudia.Stuermer@uni-konstanz.de. D01:10.1523/JNEUROSCI.0870-09.2009

Copyright $\odot 2009$ Society for Neuroscience $\quad$ 0270-6474/09/296607-09\$15.00/0 and rat (Schulte et al., 1997; Lang et al., 1998). The proteins were independently found in the floating, detergent-resistant membrane fraction and named flotillin-2 and -1, respectively (Bickel et al., 1997). The reggies form clusters at the cytoplasmic face of the plasma membrane by homo- and hetero-oligomerization (Solis et al., 2007) and serve as scaffolds for the assembly of multiprotein signaling complexes in microdomains (for review, see Stuermer and Plattner, 2005; Langhorst et al., 2005). Accordingly, the reggies were implicated in several signaling pathways, e.g., glucose transporter 4 (GLUT4) translocation (Baumann et al., 2000), src-kinase signaling (Stuermer et al., 2001), ABCA1 function (Bared et al., 2004), PrPc signaling (Stuermer et al., 2004; Málaga-Trillo et al., 2009), and cytoskeletal remodeling (Langhorst et al., 2006, 2007). In T lymphocytes, the reggies regulate cytoskeletal dynamics by recruiting the guanine-nucleotide exchange factor Vav (Langhorst et al., 2006) and in adipocytes by activating the small GTPase TC10 via c-cbl-associated protein (CAP) (Kioka et al., 2002). Since overexpression of our dominant-negative construct reggie-1EA (R1EA) perturbed axon growth in hippocampal neurons and affected filopodia length as well as Rho GTPases activation in N2a cells (Langhorst et al., 2008), we reasoned that downregulation of reggies by reggie-specific Mos may affect zebrafish (ZF) axon regeneration in vivo. Using reggie Mos in vivo and reggie-specific siRNAs in primary hippocampal neurons and N2a cells, we show here that reggies regulate ZF RGC axon regeneration in vivo, axon growth 
in vitro as well as differentiation of hippocampal neurons and process formation in N2a cell. We demonstrate that siRNAmediated downregulation of the reggies affects Rho GTPases and their downstream regulators of actin, i.e., cofilin, N-WASP, cortactin, and Arp2/3, and perturbs p38 and focal adhesion kinase (FAK) activation. Our data suggest that the reggies represent neuron-intrinsic factors crucial for successful axon regeneration, as suggested by their name and initial discovery more than 10 years ago.

\section{Materials and Methods}

Antibodies, reagents, and plasmid. AntiReggie-1 [ESA (epidermal surface antigen)], anti-cdc42, and anti-Rac1 monoclonal antibodies (mAbs) were from BD Transduction Laboratories, anti-RhoA mAb, anti-Arp3 polyclonal antibody $(\mathrm{pAB})$, and anti N-WASP $\mathrm{mAb}$ from Santa Cruz, anti-Ras $\mathrm{mAb}$ from Oncogene/Calbiochem. Anti-cofilin pAb and phosphorylation-specific pAbs against cofilin [serine 3 (Ser3)], protein kinase B (PKB) (Ser473), pan-PKC (Ser660 and homologue residues), exctracellular signal-regulated kinases 1 and 2 (ERK1/2) (Thr202/Tyr204), c-Jun N-terminal protein kinase (JNK) (Thr183/ Tyr185), FAK (Tyr576/577), and p38 (Thr180/Tyr182) were from Cell Signaling Technology, and anti-reggie- $2 \mathrm{mAb}$ from our laboratory (Lang et al., 1998). Anti-cortactin $\mathrm{mAb}$ and anti-phospho-cortactin [tyrosine 466 (Tyr466)] pAb were from Millipore Bioscience Research Reagents. Secondary HRP-, Cy3-, and Alexa-488-coupled Abs were from Jackson ImmunoResearch and Invitrogen, respectively, and Alexa Fluor Phalloidin from Invitrogen.

Cell culture and transfection. N2a neuroblastoma cells were cultivated and transfected as described previously (Langhorst et al., 2008). A mixture of three different siRNAs targeting reggie-1 (3 pmol/ml each, 9 $\mathrm{pmol} / \mathrm{ml}$ end concentration) was used for RNA interference experiments with target sequences 5' -GTTCATGGCAGACACCAAG-3' (R1.0; Dharmacon), 5'-GGTGAAGATCATGACGGAG-3' (R1.1), and 5'GGTTTATAGGCCTTCTTCC-3' (R1.4; Ambion). A commercial siRNA against firefly luciferase GL2 (Dharmacon) served as nonspecific control $(9 \mathrm{pmol} / \mathrm{ml})$. The reggie-1-enhanced green fluorescent protein (EGFP) rescue construct was generated by PCR and introducing 12 silent point mutations in the sequences targeted by R1.0 and R1.1 siRNAs [R1.4 siRNA targets a sequence in the $3^{\prime}$ untranslated region]. Thus, the reggie-1 cDNA was mutated to AttTatggcGgaTacGaaA (R1.0) and AgtCaaAatTatgacCgaA (R1.1), confirmed by sequencing, and cloned in frame into EcoRI and BamHI sites of the pEGFP-N1 vector (Clontech). The pEGFP-N1 or R1-EGFP rescue constructs were cotransfected.

For quantification of differentiation, N2a cells were cultured on laminin-coated coverslips in MEM containing $50 \mathrm{ng} / \mathrm{ml}$ insulin-like growth factor (IGF-1) (Biomol). Wide-field images were taken on an Axiovert $200 \mathrm{M}$ using a $63 \times / 1.4$ Plan-Apochromat objective and analyzed with the AxioVision 4.5 software (Carl Zeiss).

Primary hippocampal neurons were prepared from 1- to 3-d-old mice. Briefly, hippocampi were isolated, digested, and homogenized. Cells were plated on poly-L-lysine-coated coverslips in Neurobasal-A medium containing B27 supplement (Invitrogen). After $3 \mathrm{~h}$, the medium was changed to Neurobasal-A supplemented with B27, 0.5 mM L-glutamine, $1 \%$ penicillin-streptomycin, and $5 \mathrm{ng} / \mathrm{ml}$ fibroblast growth factor (Invitrogen). Neurons were transfected using Lipofectamine 2000 (Invitrogen) according to the manufacturer's instructions. After transfection (96 h), cells were fixed in $4 \%$ paraformaldehyde and mounted.

Cell lysates. GTPase assays were performed as described by Langhorst et al. (2008). Cleared cell extracts were used for coimmunoprecipitation assays: lysates were incubated with $1 \mu \mathrm{g}$ Ab against N-WASP or cortactin for $1 \mathrm{~h}$ at $4^{\circ} \mathrm{C}$. Then, $20 \mu \mathrm{l}$ of protein-G agarose (Roche) was added and incubated overnight at $4^{\circ} \mathrm{C}$. The beads were centrifuged and washed three times with ice-cold cell lysis buffer and prepared for immunoblotting. Densitometric analysis of Western blots was performed with ImageJ (Abramoff et al., 2004).

Animals, ONS, morpholino-application, and tracing. For in vivo knockdown of reggie proteins, optic nerves of zebrafish (Danio rerio), 5-13 months old, were transected under 3-aminobenzoic acid ethylester anesthesia (MS222, $0.3 \mathrm{mg} / \mathrm{ml}$; Sigma) in compliance with animal welfare legislation. Gelfoam (Pharmacia/Upjohn) soaked with morpholino (Mo) solution was applied to the proximal stump immediately after ONS (Becker et al., 2004). For specificity, two different Mo sets against reggies were simultaneously applied. Set 1: 5'-CATTTTCCTTTCTGGACG CCTTTAA-3' specific for reggie-1a, 5-'-TTTTAGACGTTGGCTGAA TGATTAG-3' for reggie-2a, 5'-CCTTAATTAGA TCGATTGCA GATAT-3' for reggie-2b; Set 2: 5'-AAAAAGCGGCTAAAGACCT AATGTT-3' for reggie-1a, 5' -CAAGAGACGCAGTAATCCAGCAGCC-3' for reggie-2a, 5' -TGTGTCAATGGTAAAGAAAACTCGC-3' for reggie-2b, and $5^{\prime}$-ATCCTGCAAAAAGAACAAGTAGCTT-3' (absent from ZF genome) as control Mo (Gene Tools). Mo concentrations from $2.5 \mu \mathrm{g} / \mu \mathrm{l}$ to $100 \mathrm{ng} / \mu \mathrm{l}$ in Ringer's solution were used to determine an effective but nontoxic concentration. In all evaluated experiments, the Gelfoam piece was soaked in $2.5 \mu \mathrm{l}$ of $312 \mathrm{ng} / \mu \mathrm{l}$ Mos. A lissamine-labeled Mo served to prove retrograde transport into RGCs.

Quantitative outgrowth assay. ZF retinas, freed from pigment epithelium and blood vessel layer, $4 \mathrm{~d}$ after ONS/Mo application, were chopped into $200 \times 200 \mu \mathrm{m}$ squares as described previously (Vielmetter and Stuermer, 1989). Mini-explants (16-24 per retina) were cultured in F12 medium, $0.4 \%$ methyl cellulose, $10 \%$ FCS, $2 \%$ chicken serum, $2 \mathrm{~mm}$ L-glutamine, $25 \mathrm{~mm}$ HEPES, penicillin $(10 \mathrm{U} / \mathrm{ml})$, streptomycin $(10 \mu \mathrm{g} /$ $\mathrm{ml}$ ) at $28.5^{\circ} \mathrm{C}$ on a poly-L-lysine coated 96 -well $\mu$ CLEAR-plate (Greiner). After 24 and $48 \mathrm{~h}$, number of axons per mini-explant was counted (Axiovert 35 microscope; Zeiss) excluding experiments with less than 9 axons per control retina explant.

In a second assay, the optic nerve of fish after ONS and Mo treatment was resectioned, respectively, 7, 10, and $14 \mathrm{~d}$ later, $2-3 \mathrm{~mm}$ distal from the first lesion, and Alexa-488-dextran (Invitrogen) was applied to ret- 
back labeled RGCs

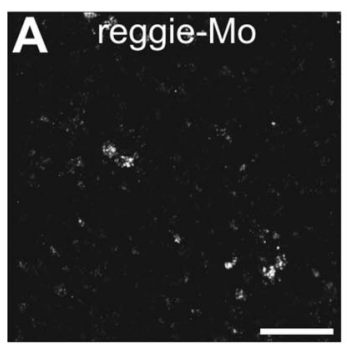

$7 d$

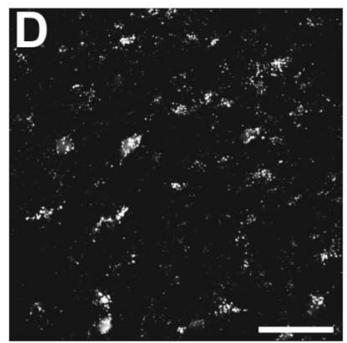

$10 d$

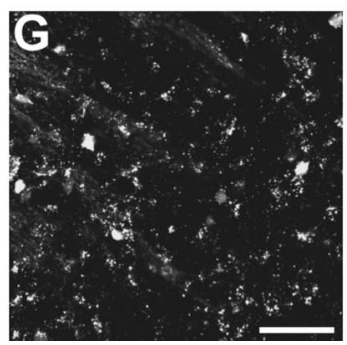

morpholinoLissamine
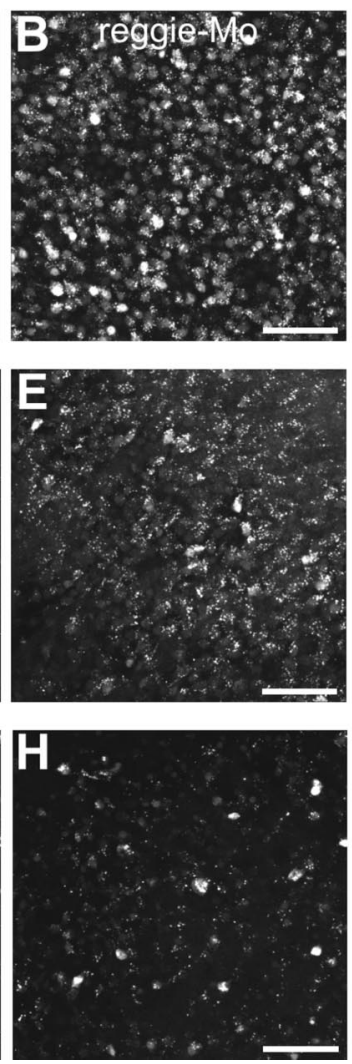

back labeled RGCs
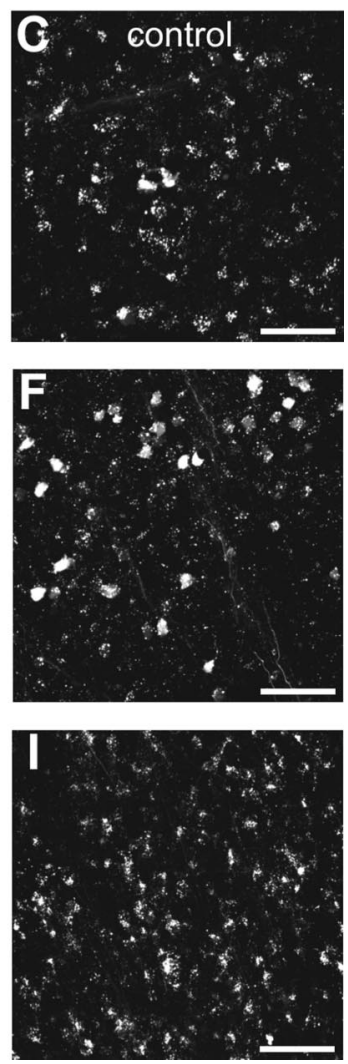

Figure 2. Mo-mediated downregulation of reggie in $\mathrm{RGCs}$ leads to a reduction of regenerating axons. Mos were applied to the ZF optic nerves as described. Alexa-488 - dextran was inserted into a second lesion site 2-3 mm distal from the first one at $7 \mathrm{~d}(\boldsymbol{A}$, $\boldsymbol{B}, \boldsymbol{C}), 10 \mathrm{~d}(\boldsymbol{D}, \boldsymbol{E}, \boldsymbol{F})$, and $14 \mathrm{~d}(\boldsymbol{G}, \boldsymbol{H}, \boldsymbol{I})$, respectively. Counts of retrogradely labeled RGCs show that their number $(\boldsymbol{A}, \boldsymbol{D}, \boldsymbol{G})$ was reduced in the reggie Mo-receiving $\mathrm{RGCS}(\boldsymbol{B}, \boldsymbol{E}, \boldsymbol{H})$ compared with the control Mo-containing $\operatorname{RGCs}(\boldsymbol{C}, \boldsymbol{F}, \boldsymbol{I})$ : by $69 \%$ at $7 \mathrm{~d}$, by $53 \%$ at $10 \mathrm{~d}$, and by $33 \%$ at $14 \mathrm{~d}$ after 0 NS. Scale bars, $50 \mu \mathrm{m}$.

rogradely label RGCs with regenerating axons. Two days later, the dextran-labeled green RGCs were counted in left and right retina whole mounts.

For microscopy analyses, retinas were prepared as mentioned above and immunostained with reggie $\mathrm{Ab}$ or directly mounted after fixation. Images were acquired on a confocal laser-scanning microscope (LSM510 META; Zeiss) with a Plan-Apochromat $40 \times / 1.3$ Plan-Neofluar objective.

\section{Results}

Reggie downregulation impairs axon regeneration

To investigate the role of the reggies in axon regeneration after ONS, reggie expression in ZF RGCs was downregulated in vivo by application of a piece of Gelfoam soaked with antisense Mo directly onto the proximal optic nerve stump (Becker et al., 2004) for retrograde Mo transport to RGCs (Fig. 1A). Since ZF possess three reggie genes, reggie-1a, reggie- $2 a$, and $-2 b$ (Málaga-Trillo et al., 2002; von Philipsborn et al., 2005), we applied a Mo mixture against all reggies to the nerve stump on the right side, which caused downregulation of reggie-1 and -2. Application of control Mo to the left side of the same fish did not alter reggie expression (Fig. $1 B, C$ ) (data not shown). Sixty-six percent of fish (six of nine) showed downregulation of reggie expression as judged by reggie $\mathrm{Ab}$ immunostainings on isolated retinas. In 33\%, downregulation failed, probably because of inefficient Mo uptake and/or transport.
The potential for axon regeneration of Mo-treated RGCs at $4 \mathrm{~d}$ after ONS was assessed by counting axons from miniexplants, at $48 \mathrm{~h}$ in culture. Right reggie Mo-treated and left control Mo-treated retinas of the same fish were analyzed for axon outgrowth in at least 16 miniexplants per retina. Retina pairs (14) showed reduced axon outgrowth from the reggie Mo-treated retina explants, which was statistically significant in 11 of the 21 fish analyzed (Fig. 1D). The reduction in axon regeneration was $44 \pm 2 \%$, when retinas without effects were substracted. Averaged over all 21 fish, including the ones without effects, reggie Mo treatment reduced the number of axons per explants by $26.9 \pm 2.3 \%$, which was highly significant $(p<0.001$, Student's $t$ test). Control Mos did not reduce axon outgrowth compared with buffer controls, confirming that the Mo concentrations had no unspecific effects.

To corroborate this finding, surgery and Mo application were performed as explained, and Alexa-488 dextran was applied $3 \mathrm{~mm}$ distal from the Mo application site, $7 \mathrm{~d}$ after ONS. This allows identification and quantification of RGCs which had regenerated their axons across the first lesion. Thus, counts of back-labeled RGCs (Fig. $2 A, C$ ) on the reggie Mo-treated side showed a significant $69 \%$ reduction compared with the number of retrogradely labeled cells on the control side (average, $31.4 \pm 2.5$ cells vs $9.8 \pm 1.2 ; p<0.001$ Student's $t$ test; $n=10$ ). Thus, reggie downregulation impairs RGC axon regeneration in vivo, implying that signal transduction pathways and cytoskeletal dynamics were affected.

It has been described that Mos in RGCs are inactivated with time (Diekmann and Stuermer, 2009) (for ZF neurolin), allowing protein production to resume. Since all cells (and not only RGCs) in the ZF retina express reggie, immunoblots are inappropriate for the determination of reggie protein re-expression over time. Instead, we evaluated the decrease in fluorescence intensity of the Mo-associated lissamine tag over retinas at, respectively, 7, 10, and $14 \mathrm{~d}$ after ONS. Lissamine fluorescence decreased significantly (by 76\%) between day 7 and 14 (Fig. $2 B, E, H$ ). This correlated with an increase in regenerating axons assessed by Alexa488 dextran application at 10 and $14 \mathrm{~d}$ after ONS. The number of retrogradely labeled RGCs was $17.6 \pm 2.2$ at $10 \mathrm{~d}(n=6)$ and $43.3 \pm 5.3$ at $14 \mathrm{~d}(n=4)$ after ONS on the reggie Mo-treated side compared with $37.1 \pm 7.0$ and $64.5 \pm 6.0(p<0.05$, Student's $t$ test) on the control side, which is a reduction of 53 and $33 \%$, respectively (Fig. 2D, F, G,I). Thus, recovery of reggie expression because of a decreasing activity of reggie-Mo in RGCs allows progressively more RGCs to regenerate their axon.

\section{Reggie-siRNAs impair hippocampal neuron differentiation}

To analyze potential defects in process formation and axon growth in individual neurons, primary hippocampal neurons isolated from 1- to 3-d-old mice were cotransfected with siRNAs 

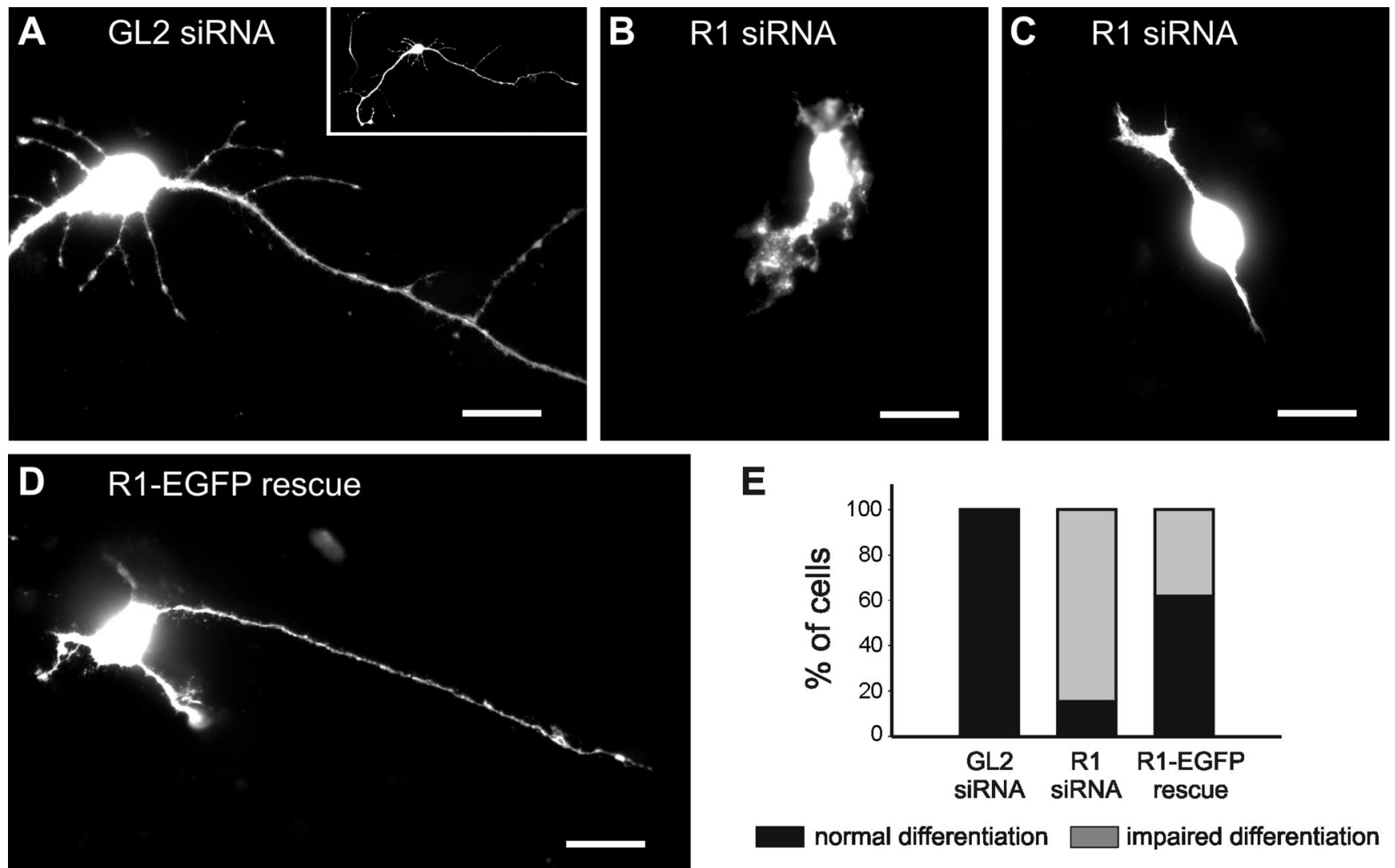

E

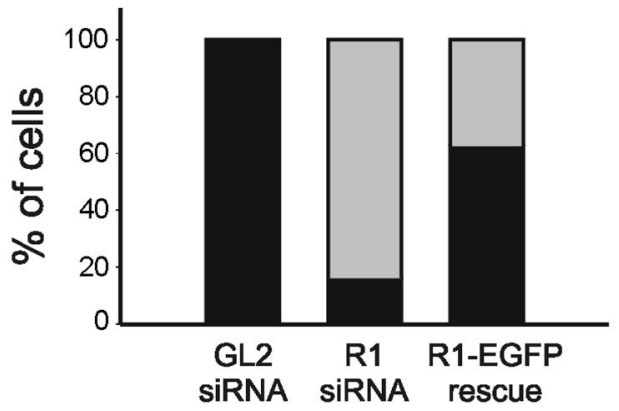

normal differentiation

Figure 3. Reggie-1 is required for hippocampal neuron differentiation. Representative wide-field images of transfected hippocampal neurons. $A$, Cells transfected with control (GL2) siRNA differentiated normally (insert) having long thin axons (to the right) and dendritic arborizations. $B$, C, Note the short and thick protrusions, large lamellipodia, and broad dendrites of reggie-1 (R1) siRNA-treated cells. D, Cells simultaneously transfected with the reggie-1 rescue construct (R1-EGFP rescue) and reggie-1 siRNAs differentiated normally. Scale bars, $20 \mu \mathrm{m}$. Histogram in $\boldsymbol{E}$ shows the quantification of the cells transfected with control GL2 siRNA, with reggie-1 siRNAs, and simultaneously transfected with R1-EGFP rescue construct and reggie-1 siRNAs.

and pEGFP. To circumvent sequence-specific off-target effects of the reggie-1 siRNA, a mix of three different sequences, each at low concentrations, was applied and led to efficient downregulation of reggie protein levels (see Fig. 4G). Transfection with control siRNA did not affect differentiation of cells (Fig. $3 A$ ). However, overexpression of reggie- 1 siRNAs in neurons resulted in severe perturbations (Fig. 3B,C). Most strikingly, $84 \%$ of the cells had neither apparent axons nor dendrites comparable with controls (Fig. 3E). Instead, hippocampal somata produced short and thick protrusions, which markedly differed from the typical shape and morphology of normal and control siRNA-transfected hippocampal neurons having long, thin axons and dendritic arborization close to the soma (Fig. $3 A-C$ ). Moreover, overexpression of reggie- 1 in cells transfected with reggie- 1 siRNA resulted in an $\sim 46 \%$ rescue of the normal cell phenotype (Fig. $3 D, E$ ), indicating that indeed reggie- 1 is involved in process formation and axon growth in hippocampal neurons.

siRNA-mediated reggie-1 downregulation in N2a cells affects process formation

To gain insights into the signal transduction pathways affected by reggie and to prove that reggie knockdown, in correlation with signaling defects, causes loss-of-function phenotypes, we used reggie1-specific siRNAs in N2a cells. The mouse N2a cells were chosen since there is no equivalent zebrafish cell line and no test kits for signal transduction pathways as available for mammalian cells. N2a cells transfected with the control siRNA showed neurite growth after IGF-1 stimulation much as the wild-type cells (Fig.
$4 A, B)$. In contrast, after transfection with the siRNA mixture, fewer cells had neurites (Fig. $4 C, E$ ), and significantly more cells formed lamellipodia (Fig. 4C,F) than control cells (74 vs $44 \%$, $p<0.001$, Student's $t$ test). Filopodia length was also significantly reduced [4.29 $\mu \mathrm{m}$ (reggie-1 siRNA) vs $5.63 \mu \mathrm{m}$ (Gl2 siRNA), $p<$ 0.001 , Student's $t$ test]. These effects were abrogated by reggie- 1 and -2 rescue experiments, thus showing that reggies regulate process formation during differentiation of N2a cells (Fig. $4 D-G)$.

\section{Depletion of reggies interferes with Rho GTPase activation and signal transduction in N2a cells}

The phenotypes of reggie downregulated cells suggested an effect on cytoskeletal remodelling and activation of Rho family small GTPases (Hall, 1998; Langhorst et al., 2008). GST pulldowns with minimal binding domains of effector proteins specific for the GTP-bound form of the GTPase (de Rooij and Bos, 1997) were, therefore, performed, including a quantitative assessment of the signals. The activation patterns of RhoA, Rac1, and cdc42 were significantly altered (Fig. 5A-C). IGF-1 application increased the activation of RhoA and Racl in control-transfected cells, whereas siRNA-treated cells showed an elevated level of activated RhoA and Rac1 without IGF-1, which further increased during IGF stimulation (Fig. 5A,C). In contrast, cdc42 activity decreased during IGF application in control-transfected cells and remained at low levels in siRNA-transfected cells with or without IGF-1 (Fig. 5B).

The disturbance of the balanced activation of the Rho-GT- 

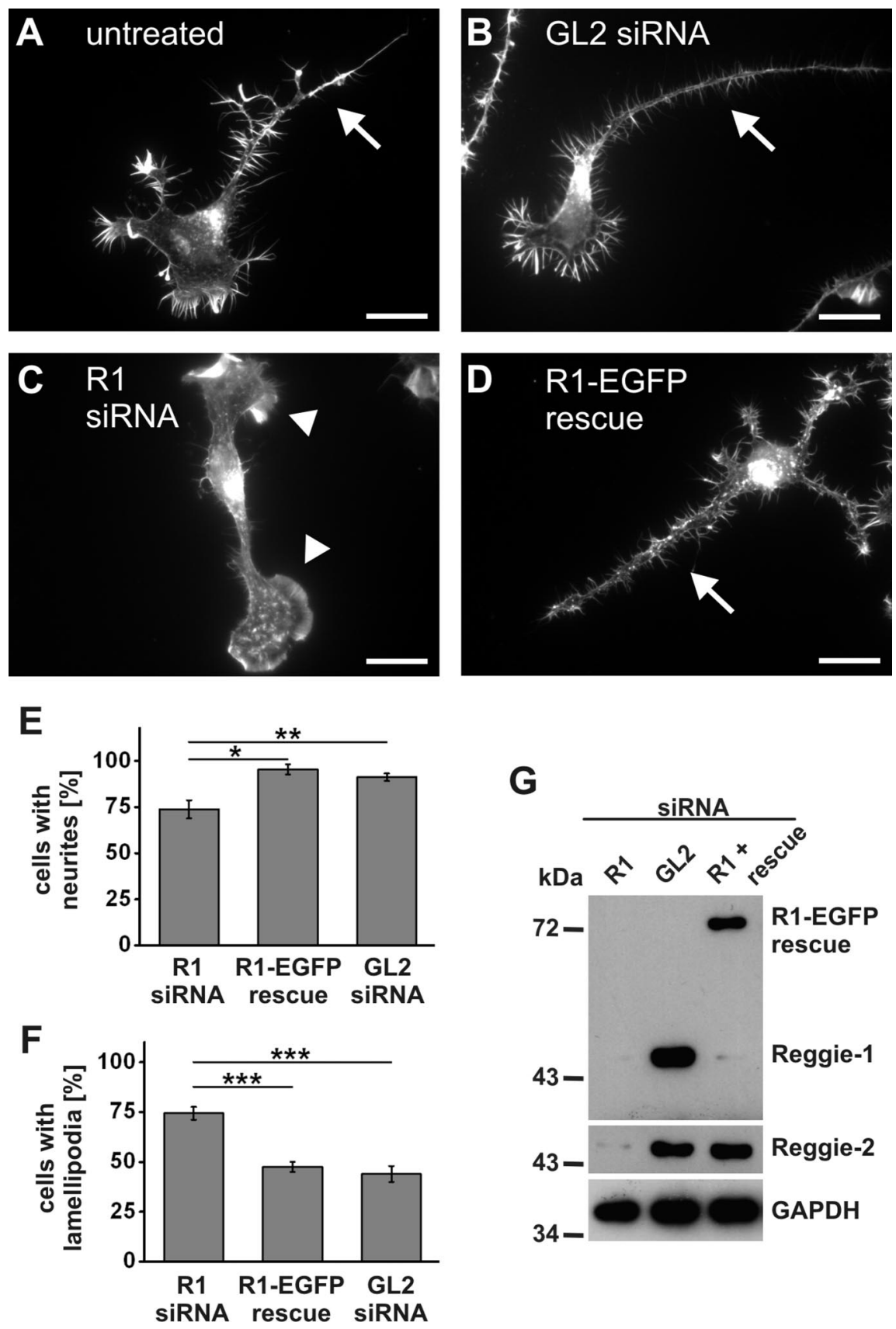

Figure 4. Reggie-1 knockdown impairs process formation in N2a cells. Cells transfected with either GL2 control siRNAs or a mix of reggie-1-specific siRNAs were stimulated with IGF-1, fixed $24 \mathrm{~h}$ after stimulation, and stained with phalloidin to visualize F-actin and cell morphology. Untreated and GL2 siRNA-transfected cells produced numerous filopodia $(\boldsymbol{A}, \boldsymbol{B})$, whereas reggie-1 downregulation (R1 siRNA) led to the formation of large lamellipodia $(\boldsymbol{F})$. Significantly fewer cells formed neurites after reggie-1 siRNA transfection $(\boldsymbol{E})$, which efficiently downregulated reggie-1 and reggie-2 expression compared with GL2 siRNA cells in Western blot experiments (G). D, N2a cells were simultaneously transfected with reggie-1 siRNA and the reggie-1 construct (R1-EGFP rescue) without siRNA-binding sites. A large proportion of the cells no longer exhibited the lamellipodia-rich phenotype but had instead many filopodia and neurites $(\boldsymbol{D}-\boldsymbol{F})$ much as control cells $(\boldsymbol{A}, \boldsymbol{B})$. Mean $\pm \mathrm{SEM} ;{ }^{*} p<0.05,{ }^{* *} p<0.01,{ }^{* * *} p<$ 0.001 , Student's $t$ test. Scale bars, $20 \mu \mathrm{m}$.

Pases in reggie siRNA-treated cells and the dramatic phenotype in response to this treatment suggests that reggie downregulation affects the activation of actin-binding proteins which modulate actin cytoskeleton dynamics. Therefore, we examined the activation state of representative regulatory proteins downstream of the Rho GTPases, such as N-WASP, cortactin, Arp3, and cofilin.

The Arp2/3 complex is an actin-nucleating factor, which requires direct interaction with N-WASP and cortactin, respec- tively (Le Clainche and Carlier, 2008), for its activation by Rho GTPases. Therefore, we analyzed by coimmunoprecipitation whether N-WASP, cortactin, and Arp3 form a complex in N2a cells and whether this goes along with Tyr466 phosphorylation of cortactin. In IGF-1-treated control cells, the association of Arp3 with $\mathrm{N}$-WASP and cortactin was lower than in unstimulated control cells (Fig. 6A). In contrast, reggie-1 siRNA-treated cells showed a marked reduction in the formation of N-WASP-Arp3, cortactin-Arp3 and N-WASP-cortactin complexes, particularly after IGF-1 stimulation (Fig. 6A). Furthermore, downregulation of reggie-1 strongly reduced the Tyr466 phosphorylation level of cortactin (with or without IGF-1 treatment) when compared with control-transfected N2a cells (Fig. 6B).

The Arp2/3 complex is reported to interact with the actin depolymerization factor cofilin (Le Clainche and Carlier, 2008). As activation of cofilin requires dephosphorylation of its Ser3, which is needed for the differentiation of primary neurons and PC12 cells (Meberg and Bamburg, 2000; Endo et al., 2007), we analyzed changes of the activation state of cofilin in N2a cells during IGF-induced differentiation. In control cells, Ser3 phosphorylation of cofilin was slightly reduced by IGF-1 stimulation (Fig. 6C) but remained markedly elevated after reggie-1 downregulation (with or without IGF-1).

Using phospho-specific Abs against further key signaling proteins, we also tested whether reggie-1 siRNA would interfere with activation of other signaling pathways. Interestingly, activation of p38 was drastically reduced in reggie siRNAtreated cells in comparison with control cells, and this was apparently not affected by IGF (Fig. 7A). In addition, tyrosine phosphorylation of FAK at residues 567 and 577 was strongly reduced in reggie siRNA-treated cells (Fig. 7C). Moreover, results suggest an apparent downregulation of the total amount of FAK during reggie-1 siRNA treatment.

Thus, reggie knockdown leads to an imbalanced activation of the small GTPases of the Rho family, which in turn affect the activation state of actin regulators, i.e., cofilin, N-WASP, cortactin, and Arp2/3, so that reggie downregulation can impair cytoskeleton dynamics required for axon growth and regeneration. Moreover, reggie downregulation affects p38 and FAK activation, which correlates with the disturbance in $\mathrm{N} 2$ a cell process formation, in axon growth of hippocampal neurons and axon regeneration in vivo (Ivankovic-Dikic et al., 2000; Takeda and Ichijo, 2002; Burridge and Wennerberg, 2004).

Ras stimulation by IGF in control transfectants was absent in 
reggie siRNA-treated cells (Fig. 5A), and MAP kinase ERK1/2 phosphorylation was decreased (Fig. $7 B$ ), which corresponds to a reduction of cell growth to $63 \%$ in response to siRNA treatment (data not shown). No effects were seen on the IGFinduced phosphorylation of the MAP kinase JNK and the phosphorylation of PKB and PKC (Fig. 7D). These results suggest that blockage of reggie function interferes with signaling pathways regulating the actin cytoskeleton cell substrate interaction and cell proliferation.

\section{Discussion}

Reggie- 1 and reggie-2 are upregulated in RGCs after ONS and are indicative of the neuron-intrinsic properties of fish CNS neurons which enable them to regenerate axons. That reggie re-expression is indeed causally linked to process formation in cells in vitro and regeneration in vivo is shown by our present experiments. Inhibition of reggie expression impaired ZF axon regeneration and blocked axon growth and dendrite arborizations in primary hippocampal neurons. Perturbation of reggie expression also affected process formation in N2a cells in correlation with an imbalanced activation of the Rho GTPases and their downstream targets: it impaired the activation of cofilin and phosphorylation of cortactin and the formation of the N-WASP, cortactin, and Arp2/3 complex, and thus regulates actin cytoskeleton dynamics. The regulators of process formation and growth, p38, and FAK are further downstream targets of the reggies, a finding supported by our recent results showing effects of reggie on focal adhesion dynamics (Langhorst et al., 2008; Schrock et al., 2009). Thus, reggies regulate regeneration and axon growth in vivo and in vitro assays.

The retinal explants of Mo-treated fish in the in vivo experiments gave rise to significantly fewer axons. Likewise, the number of regenerating axons at $7 \mathrm{~d}$ after lesion was reduced by $69 \%$ after reggie-Mo application, indicating that axon extension from reggie Mo-affected RGCs is strongly impaired. Growth inhibition did not occur in all retinas of Mo-treated fish to the same extent, probably because of insufficient Mo uptake in result of suboptimal positioning of the Mo-filled gelfoam piece. Such or other technical problems (like suboptimal surgery during ONS) could account for the one-third of reggie Mo-treated retinas with mean number of axons per explant similar to controls. The difference of $30 \%$ in vitro versus $69 \%$ in vivo growth inhibition can be attributed to the different techniques. In the outgrowth assay, axons are outside of the lesioned optic nerve and its myelin debris, glial cells, and macrophages/microglia, and are lesioned (for the second time) close to the cell body which stimulates regrowth.

The drawback of applying Mos in vivo is their gradual inactivation in the target cells leading to gradual protein re-expression
B

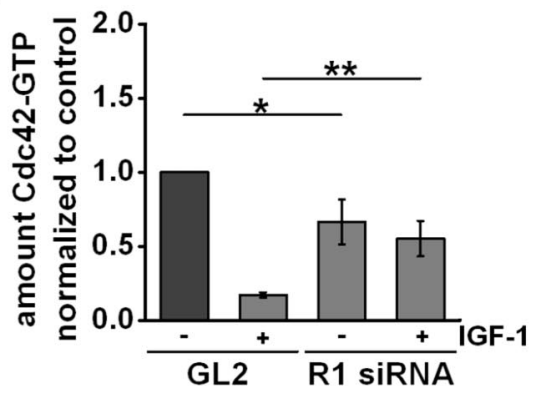

Figure 5. Reggie-1 downregulation affects Rho GTPase activation in N2a cells. N2a cells starved overnight, stimulated with 50

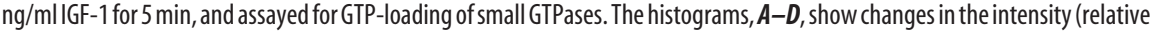
to controls) in the respective Western blots $(n=4)$, which are exemplified below each histogram. Mean $\pm \mathrm{SEM} ;{ }^{*} p<0.05$, $p<0.01, * 0<0.001$, Student's test. Total Rac, cdc 42, RhoA, and Ras of crude lysates were used as loading control. $A, B$ transfected cells and remained at low levels in siRNA-transfected cells with or without IGF-1.C RhoA activation increased during IGF application in control cells and further increased in reggie-1 siRNA-treated cells. $\boldsymbol{D}$, Ras stimulation by IGF in control transfectants was absent in reggie-siRNA-treated cells.

(Diekmann and Stuermer, 2009) (for ZF RGCs). The decrease in intensity of the reggie-Mo-associated fluorescent tag allowed for an estimation of the Mo inactivation which-in turn-correlated with an increase in axon regeneration. It is unfortunately impossible to renew the Mo-mediated blockage of protein reexpression, as this would require resectioning of the fastregenerating axons without obtaining access to the axons regenerating more slowly. In essence, this implies that axon regeneration in vivo is transiently impaired along with the transient Mo-mediated block of reggie expression.

In our in vivo experiments, reggie Mos block most likely the lesion-induced upregulation of the reggie proteins which are, evidently, needed for the formation of new axons. That the morphology of the somata and dendrites of the adult RGCs would be affected is less likely, although we did not examine this issue explicitly. In differentiating neurons, however, reggie downregulation by siRNAs impaired process extension in N2a cells and 
A

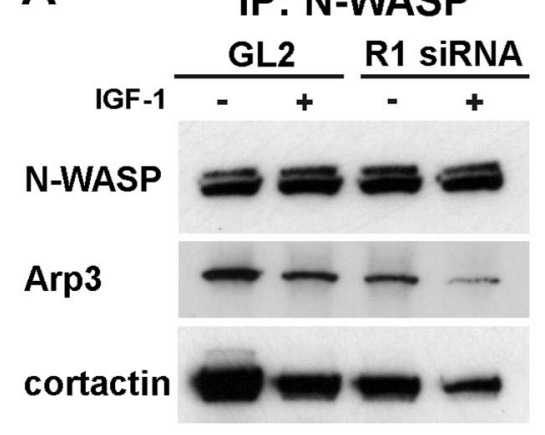

B

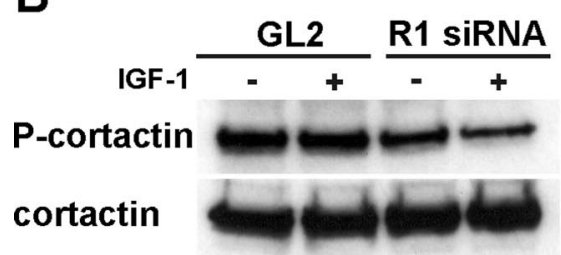

\section{IP: cortactin} GL2 R1 siRNA

$+\quad+\quad+$ IGF-1

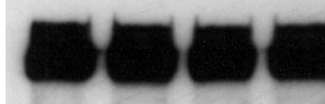

cortactin

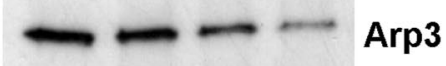

$--\longrightarrow \begin{gathered}\text { Input } \\ \text { Arp3 }\end{gathered}$

C

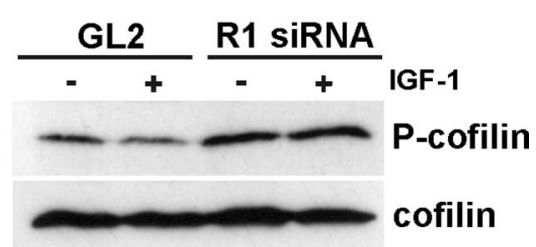

Figure 6. Coimmunoprecipitation assays for the analysis of the complex of Arp3, N-WASP, and cortactin and phosphorylation of cofilin and cortactin in reggie siRNA-treated N2a cells. $\boldsymbol{A}$, In IGF-1 stimulated control cells, Abs against N-WASP and cortactin coprecipitate Arp3. In reggie-1 siRNA-treated cells, the Arp3, N-WASP, cortactin complex is present at lower levels and is almost disrupted during IGF stimulation. $B$, The phosphorylation of cortactin at Tyr466 is unchanged after IGF-1 treatment of control cells but is strongly reduced during IGF-1 treatment of reggie-1 siRNA cells. C, The phosphorylation of cofilin at Ser3 slightly decreases during IGF stimulation but is increased in reggie-1 siRNA-treated cells with or without IGF-1.

often prevented both the formation of long dendrites and axons in hippocampal neurons, which resulted in enlarged somata and broad stubby protrusions, or dendrites were present but the axons were short, ended in conspicuous bulbs, and failed to elongate. Such bulbs were previously noticed in hippocampal neurons after transfection with the dominant-negative R1EA construct (Langhorst et al., 2008), thus supporting our conclusion that reggie microdomains are needed for axon growth and regeneration.

Although reggie Mos and siRNAs downregulate protein expression, transfection with the dominant-negative R1EA does not impair reggie-1 protein production so that reggie-2, whose stability depends on the presence of reggie-1 (Solis et al., 2007), is retained at normal concentrations. Our earlier work suggests that R1EA prevents reggie-1 from associating with plasma membrane microdomains (Langhorst et al., 2006; Solis et al., 2007). Since bulb-shaped endings emerged in R1EA overexpressing cells as well as in cells lacking reggie-1 and reggie-2, we propose that reggie microdomains at the neuron's plasma membrane are necessary units for axon growth (hippocampal neurons) and process extension (N2a cells). This implies that both expression levels and appropriate positioning of reggie- 1 and -2 are important for process extension and axon growth and correlates with earlier observations that reggie microdomains are, in fact, reformed in regenerating fish RGC axons (Lang et al., 1998; Stuermer et al., 2001). The disturbance of Ras and ERK1/2 activation provoked by siRNA-mediated downregulation of reggie- 1 correlates with the reduced $\mathrm{N} 2 \mathrm{a}$ cell growth. These data are in agreement with the work of Santamaria et al. (2005) showing the requirement of reggie-2 for normal cell proliferation. Conversely, R1EA had no effect on $\mathrm{N} 2$ a cell growth.

All experimental evidence that we have collected over the years agrees with our hypothesis that reggie microdomains represent centers for protein complex formation and signal transduction to the cytoskeleton (Stuermer et al., 2004; Stuermer and
Plattner, 2005; Schrock et al., 2009). This view is consistent with the model proposed by Kioka et al. (2002) for mobilization of GLUT4 from internal stores.

Reggies bind CAP and src-tyrosine kinases (Baumann et al., 2000; Stuermer et al., 2004; Liu et al., 2005) so that various downstream signaling molecules can be activated such as the atypical small GTPase TC10 (Kioka et al., 2002). Our present study shows cytoskeletal remodeling, necessary for axon growth by FAK, p38, Rho family GTPases (Takeda and Ichijo, 2002; Burridge and Wennerberg, 2004; Govek et al., 2005), and downstream targets such as the N-WASP, Arp2/3, cortactin complex, and cofilin. The Arp2/3 complex has been studied extensively in migrating cells and much less is known on its regulatory function during the differentiation of neurons, yet its components seem to be involved in neuritogenesis in vitro and are triggered by the regulated interaction of different Rho GTPases (Banzai et al., 2000; Pommereit and Wouters, 2007; Korobova and Svitkina, 2008; Mingorance-Le Meur and O'Connor, 2009). RhoA in general inhibits, whereas Rac1 and cdc42 stimulate, process outgrowth (for review, see Govek et al., 2005). However, live imaging shows that RhoA, Rac1, and cdc42 undergo repetitive activation cycles at motile protrusions and different locations of their respective peak activity (Aoki et al., 2004; Kurokawa et al., 2005; Nakamura et al., 2005). Therefore, balanced activation and positioning of Rho-GTPases regulates successful process extension and axon regeneration via downstream regulators of actin dynamics. The Rho GTPases also affect microtubule dynamics during stabilization of the outgrowing neurite (da Silva and Dotti, 2002); thus, impaired axon regeneration may also result from defects in microtubule stabilization.

Since reggie microdomains are platforms for clustering of specific GPI-anchored proteins (in response to GPI-protein activation) of src tyrosine kinases, CAP, and regulators of actin dynamics, we speculate that axon regeneration defects should not only occur after downregulation of reggie but also through blockage of function and/or assembly of specific glycosylphosphatidylinositol (GPI)-anchored and signaling proteins associated with reggie microdomains (Stuermer et al., 2004).

New studies have suggested that GPI-anchors with long acyl chains can dynamically interact with long alkyl chain-containing sphingolipids, which allows an interaction with the cortical actin cytoskeleton without the need for transmembrane proteins as mediators for GPI-anchored protein signal transduction (Goswami et al., 2008; Niemelä et al., 2009). Reggie microdomains seem to demarcate such "hot spots" for specific lipids and lipidanchored proteins (Stuermer et al., 2004). In these domains, reggies seem to function as regulators of actin dynamics (this study; Langhorst et al., 2007) triggered by clustering of specific GPIanchored proteins. Favorite associates of reggie microdomains are, for instance, PrPc, Thy-1, and F3, which coimmunoprecipitate with reggie (Stuermer et al., 2001, 2004) and which gain access to the signal transduction machinery regulating actin dynamics by clustering in reggie microdomains. Moreover, $\mathrm{PrPc}$ promotes signal transduction in association with reggie in the $\mathrm{T}$ 


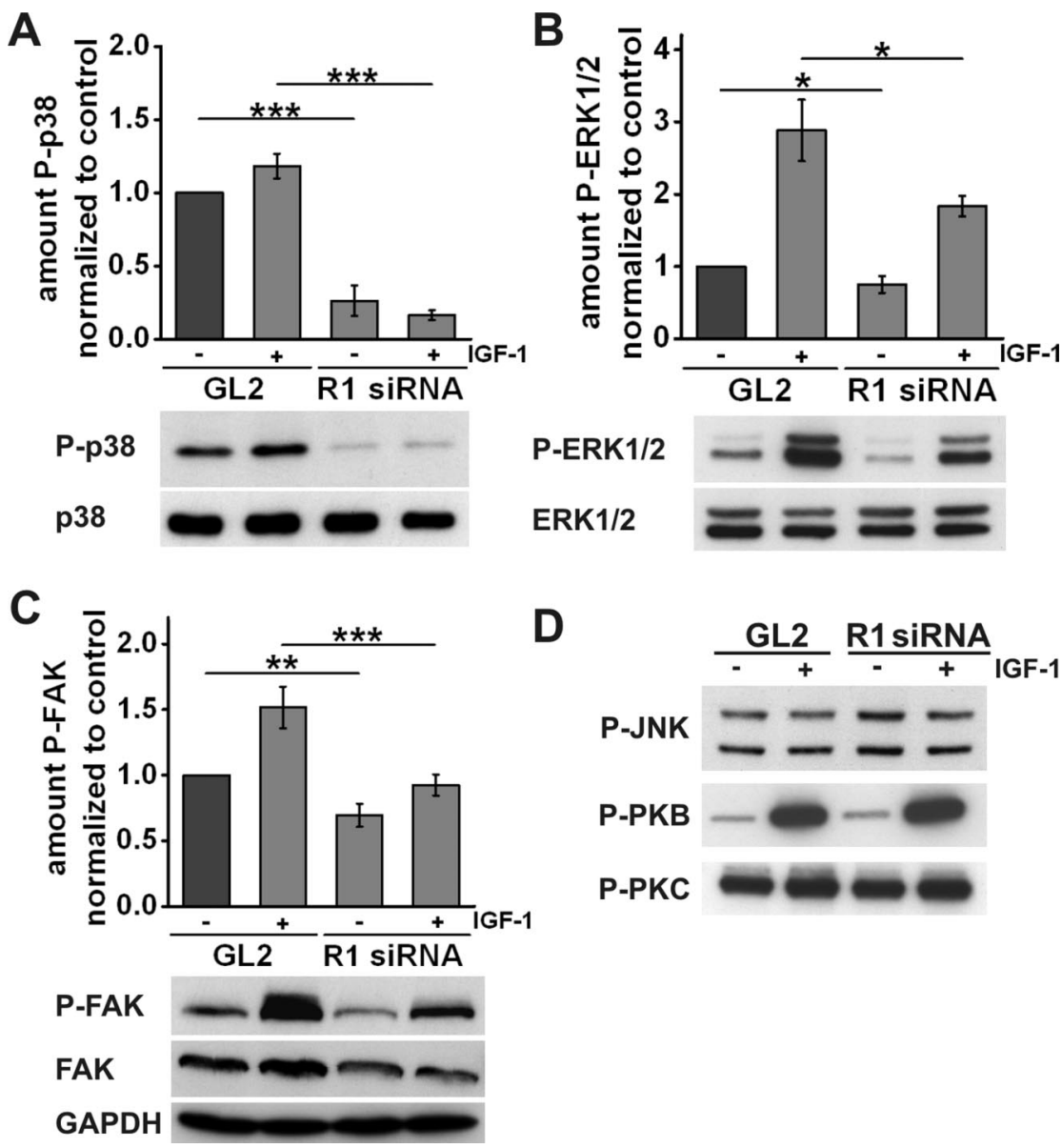

Figure 7. Reggie-1 downregulation affects signaling in N2a cells. $A$, Activation of $\mathrm{p} 38$ was reduced in reggie siRNA-treated cells independently of IGF-1 stimulation in comparison with control transfectants. $\boldsymbol{B}$, ERK1/2 activation was decreased in response to reggie siRNA. $C$, pFAK showed a significant activation during IGF-1 stimulation, and this stimulation was reduced in reggie-1 siRNA-treated cells. Total FAK was decreased in reggie-1 siRNA-treated cells. Total p38 ( $\boldsymbol{A})$, ERK1/2 (B), and GAPDH ( $\boldsymbol{C}$ ) were used as loading controls. Mean \pm SEM; $n=4 ;{ }^{*} p<0.05,{ }^{* *} p<0.01$, ${ }^{* * *} p<0.001$, Student's $t$ test. $\boldsymbol{D}$, JNK, PKC, and PKB phosphorylation was not affected by reggie-1 siRNA-treatment.

cell cap via ERK1/2 and a transient $\mathrm{Ca}^{2+}$ rise (Stuermer et al., 2004). Furthermore, Thy-1 has been demonstrated to be upregulated in fish RGCs (Schulte et al., 1997; Lang et al., 1998), much like the reggies, so that a potential contribution of Thy-1 to axon regeneration might be elucidated in the context of reggieassociated signal transduction.

Together, our results show that reggies function in process formation in vitro and axon regeneration in vivo, as suggested more than a decade ago, and point to the importance of microdomains in coordinated signal transduction. Since rat RGCs which regenerate few axons in the presence of a peripheral nerve graft re-express reggie (and only these RGCs show reggie upregulation) (Lang et al., 1998), it will be interesting to examine if reggies are necessary for axon regrowth in mammals.

\section{References}

Abramoff MD, Magelhaes PJ, Ram SJ (2004) Image processing with ImageJ. Biophotonics Int 11:36-42.

Aoki K, Nakamura T, Matsuda M (2004) Spatio-temporal regulation of Rac1 and Cdc42 activity during nerve growth factor-induced neurite outgrowth in PC12 cells. J Biol Chem 279:713-719.

Banzai Y, Miki H, Yamaguchi H, Takenawa T (2000) Essential role of neural Wiskott-Aldrich syndrome protein in neurite extension in PC12 cells and rat hippocampal primary culture cells. J Biol Chem 275:11987-11992.

Bared SM, Buechler C, Boettcher A, Dayoub R, Sigruener A, Grandl M, Rudolph C, Dada A, Schmitz G (2004) Association of ABCA1 with syntaxin
13 and flotillin-1 and enhanced phagocytosis in tangier cells. Mol Biol Cell 15:5399-5407.

Baumann CA, Ribon V, Kanzaki M, Thurmond DC, Mora S, Shigematsu S, Bickel PE, Pessin JE, Saltiel AR (2000) CAP defines a second signalling pathway required for insulinstimulated glucose transport. Nature 407:202-207.

Becker CG, Lieberoth BC, Morellini F, Feldner J, Becker T, Schachner M (2004) L1.1 is involved in spinal cord regeneration in adult zebrafish. J Neurosci 24:7837-7842.

Bickel PE, Scherer PE, Schnitzer JE, Oh P, Lisanti MP, Lodish HF (1997) Flotillin and epidermal surface antigen define a new family of caveolae-associated integral membrane proteins. J Biol Chem 272:13793-13802.

Burridge K, Wennerberg K (2004) Rho and Rac take center stage. Cell 116:167-179.

Chen MS, Huber AB, van der Haar ME, Frank M, Schnell L, Spillmann AA, Christ F, Schwab ME (2000) Nogo-A is a myelinassociated neurite outgrowth inhibitor and an antigen for monoclonal antibody IN-1. Nature 403:434-439.

da Silva JS, Dotti CG (2002) Breaking the neuronal sphere: regulation of the actin cytoskeleton in neuritogenesis. Nat Rev Neurosci 3:694-704.

de Rooij J, Bos JL (1997) Minimal Ras-binding domain of Rafl can be used as an activationspecific probe for Ras. Oncogene 14:623-625.

Diekmann H, Stuermer CAO (2009) Zebrafish neurolin-a and -b, orthologs of ALCAM, are involved in retinal ganglion cell differentiation and retinal axon pathfinding. J Comp Neurol 513:38-50.

Diekmann H, Klinger M, Oertle T, Pogoda M, Heinz D, Schwab ME, Stuermer CAO (2005) Evidence for the absence of the neurite growth inhibitory protein Nogo-A in fish. JME 22:1635-1648.

Endo M, Ohashi K, Mizuno K (2007) LIM kinase and slingshot are critical for neurite extension. J Biol Chem 282:13692-13702.

Fawcett JW (1992) Intrinsic neuronal determinants of regeneration. Trends Neurosci 15:5-8.

Goswami D, Gowrishankar K, Bilgrami S, Ghosh S, Raghupathy R, Chadda R, Vishwakarma R, Rao M, Mayor S (2008) Nanoclusters of GPI-anchored proteins are formed by cortical actin-driven activity. Cell 135:1085-1097.

Govek EE, Newey SE, Van Aelst L (2005) The role of the Rho GTPases in neuronal development. Genes Dev 19:1-49.

Hall A (1998) Rho GTPases and the actin cytoskeleton. Science 279:509-514.

Ivankovic-Dikic I, Grönroos E, Blaukat A, Barth BU, Dikic I (2000) Pyk2 and FAK regulate neurite out-growth induced by growth factors and integrins. Nat Cell Biol 2:574-581.

Kim WY, Snider WD (2008) Overcoming inhibitions. Science 322:869-872.

Kioka N, Ueda K, Amachi T (2002) Vinexin, CAP/ponsin, ArgBP2: a novel adaptor protein family regulating cytoskeletal organization and signal transduction. Cell Struct Funct 27:1-7.

Korobova F, Svitkina T (2008) Arp2/3 complex is important for filopodia formation, growth cone motility, and neuritogenesis in neuronal cells. Mol Biol Cell 19:1561-1574.

Kurokawa K, Nakamura T, Aoki K, Matsuda M (2005) Mechanism and role of localized activation of Rho-family GTPases in growth factorstimulated fibroblasts and neuronal cells. Biochem Soc Trans 33:631-634.

Lang DM, Lommel S, Jung M, Ankerhold R, Petrausch B, Laessing U, Wiechers MF, Plattner H, Stuermer CA (1998) Identification of reggie-1 and reggie-2 as plasmamembrane-associated proteins which cocluster with 
activated GPI-anchored cell adhesion molecules in non-caveolar micropatches in neurons. J Neurobiol 37:502-523.

Langhorst MF, Reuter A, Stuermer CA (2005) Scaffolding microdomains and beyond: the function of reggie/flotillin proteins. Cell Mol Life Sci 62:2228-2240.

Langhorst MF, Reuter A, Luxenhofer G, Boneberg EM, Legler DF, Plattner H, Stuermer CA (2006) Preformed reggie/flotillin caps: stable priming platforms for macrodomain assembly in T cells. FASEB J 20:711-713.

Langhorst MF, Solis GP, Hannbeck S, Plattner H, Stuermer CAO (2007) Linking membrane microdomains to the cytoskeleton: regulation of the lateral mobility of reggie-1/flotillin- 2 by interaction with actin. FEBS Lett 514:4697-46703.

Langhorst MF, Jaeger FA, Mueller S, Sven Hartmann L, Luxenhofer G, Stuermer CA (2008) Reggies/flotillins regulate Rho GTPase signalling during axon outgrowth and axon regeneration. Eur J Cell Biol 87:921-931.

Le Clainche C, Carlier MF (2008) Regulation of actin assembly associated with protrusion and adhesion in cell migration. Physiol Rev 88:489-513.

Liu J, Deyoung SM, Zhang M, Dold LH, Saltiel AR (2005) The Stomatin/ Prohibitin/Flotillin/HflK/C domain of flotillin-1 contain distinct sequences that direct plasma membrane localization and protein interactions in 3T3-L1 adipocytes. J Biol Chem 280:16125-16134.

Málaga-Trillo E, Laessing U, Lang DM, Meyer A, Stuermer CAO (2002) Evolution of duplicated reggie genes in zebrafish and goldfish. J Mol Evol 54:235-245.

Málaga-Trillo E, Solis GP, Schrock Y, Geiss C, Luncz L, Thomanetz V, Stuermer CAO (2009) Regulation of embryonic cell adhesion by the prion protein. PLoS Biol 7:e55.

Meberg PJ, Bamburg JR (2000) Increase in neurite outgrowth mediated by overexpression of actin depolymerizing factor. J Neurosci 20:2459-2469.

Mingorance-Le Meur A, O'Connor TP (2009) Neurite consolidation is an active process requiring constant repression of protrusive activity. EMBO J 28:248-260.

Nakamura T, Aoki K, Matsuda M (2005) FRET imaging in nerve growth cones reveals a high level of RhoA activity within the peripheral domain. Brain Res Mol Brain Res 139:277-287.

Niemelä PS, Hyvönen MT, Vattulainen I (2009) Atom-scale molecular interactions in lipid raft mixtures. Biochim Biophys Acta 1788:122-135.

Pommereit D, Wouters FS (2007) An NGF-induced Exo70-TC10 complex locally antagonises Cdc42-mediated activation of N-WASP to modulate neurite outgrowth. J Cell Sci 120:2694-2705.
Santamaría A, Castellanos E, Gómez V, Benedit P, Renau-Piqueras J, Morote J, Reventós J, Thomson TM, Paciucci R (2005) PTOV1 enables the nuclear translocation and mitogenic activity of flotillin-1, a major protein of lipid rafts. Mol Cell Biol 25:1900-1911.

Schrock Y, Solis GP, Stuermer CA (2009) Regulation of focal adhesion formation and filopodia extension by the cellular prion protein (PrPC). FEBS Lett 583:389-393.

Schulte T, Paschke KA, Laessing U, Lottspeich F, Stuermer CA (1997) Reggie-1 and reggie-2, two cell surface proteins expressed by retinal ganglion cells during axon regeneration. Development 124:577-587.

Solis GP, Hoegg M, Munderloh C, Schrock Y, Malaga-Trillo E, Rivera-Milla E, Stuermer CA (2007) Reggie/flotillin proteins are organized into stable tetramers in membrane microdomains. Biochem J 403:313-322.

Stuermer CA, Leppert C (2000) Molecular determinants of retinal axon pathfinding in fish. In: Axonal regeneration in the central nervous system (Ingoglia NA, Murray M, eds), pp 19-44. New York: Marcel Dekker.

Stuermer CA, Plattner H (2005) The 'lipid raft' microdomain proteins reggie-1 and reggie-2 (flotillins) are scaffolds for protein interaction and signalling. Biochem Soc Symp 72:109-118.

Stuermer CA, Bastmeyer M, Bähr M, Strobel G, Paschke K (1992) Trying to understand axonal regeneration in the CNS of fish. J Neurobiol 23:537-550.

Stuermer CA, Lang DM, Kirsch F, Wiechers M, Deininger SO, Plattner H (2001) Glycosylphosphatidyl inositol-anchored proteins and fyn kinase assemble in noncaveolar plasma membrane microdomains defined by reggie-1 and -2. Mol Biol Cell 12:3031-3045.

Stuermer CA, Langhorst MF, Wiechers MF, Legler DF, Von Hanwehr SH, Guse AH, Plattner H (2004) PrPc capping in T cells promotes its association with the lipid raft proteins reggie-1 and reggie-2 and leads to signal transduction. FASEB J 18:1731-1733.

Takeda K, Ichijo H (2002) Neuronal p38 MAPK signalling: an emerging regulator of cell fate and function in the nervous system. Genes Cells 7:1099-1111.

Vielmetter J, Stuermer CA (1989) Goldfish retinal axons respond to position-specific properties of tectal cell membranes in vitro. Neuron 2:1331-1339.

von Philipsborn AC, Ferrer-Vaquer A, Rivera-Milla E, Stuermer CA, MálagaTrillo E (2005) Restricted expression of reggie genes and proteins during early zebrafish development. J Comp Neurol 482:257-272. 